\title{
VOLUNTURISMO: UMA ABORDAGEM CONCEITUAL
}

\author{
VOLUNTURISMO: A CONCEPTUAL APPROACH \\ VOLUNTURISMO: UN ABORDAJE CONCEPTUAL
}

Thaís Cristine Mendes

E-mail: mendesthais@live.com Universidade Federal do Rio Grande do Norte.

Bacharel em Turismo.

Kerlei Eniele Sonaglio

E-mail: kerlei@ufrnet.br Universidade Federal do Rio Grande do Norte. Doutora em Engenharia Ambiental. Mestre em Engenharia Ambiental. Especialista em Turismo Empreendedor. Bacharel em Turismo.

Data de Submissão: 12/06/2012

Data de Aprovação: 07/05/2013

RESUMO

Esclarecer o que é "volunturismo" partindo de uma abordagem conceitual é premente para que se obtenha melhor compreensão sobre suas práticas e a relação entre "turismo" e "voluntariado". Além disso, é a partir do entendimento teórico/conceitual que se baseiam as estratégias de intervenção e gestão de um segmento turístico, visando à sua sustentabilidade. Assim, na intenção de contribuir com o esclarecimento e o debate teórico/conceitual acerca do volunturismo se apresentam as principais diferenças e similaridades encontradas sobre o voluntariado e o volunturismo e expõe-se análise conceitual e interpretativa sobre o segmento. Então, partiu-se do estudo qualitativo pautado na pesquisa exploratória, utilizando-se da pesquisa bibliográfica e eletrônica. Por fim, exibe-se o ensaio conceitual sobre o volunturismo, que foi elaborado no findar do estudo.

PALAVRAS-CHAVE: Turismo. Voluntariado. Volunturismo.

\begin{abstract}
In order to clarify what "voluntourism" is, starting with a conceptual approach, it is necessary to have a better understanding of its practices as well as its relationship to the foundational elements such as "tourism" and "voluntary". In addition, it is from the theoretical and conceptual understanding that the strategies of intervention and management of a touristic segment are formed, in order to develop tourism in a sustainable way. Therefore, with the aim of contributing to the clarification and the current theoretical and conceptual debate surrounding voluntourism, this text introduces the main differences and similarities between volunteer work and voluntourism, and presents a conceptual analysis and interpretation of the voluntouristic segment. It starts with a qualitative study of the themes in question, based on exploratory research in the literature and online databases. Finally, it presents a conceptual essay on voluntourism, written at the end of the study.
\end{abstract}

KEYWORDS: Tourism. Volunteering. Voluntourism. 
Es apremiante aclarar lo que se entiende por "volunturismo" partiendo de un abordaje conceptual para lograr una mejor comprensión sobre sus prácticas y la relación entre "turismo" y "voluntariado". Además, a partir del entendimiento teórico/conceptual se fundamentan las estrategias de intervención y gestión de un segmento turístico, apuntando a su sostenibilidad. Así, con la intención de contribuir con el esclarecimiento y el debate teórico/conceptual acerca del volunturismo, se presentan las principales diferencias y semejanzas encontradas sobre el voluntariado y el volunturismo y se expone el análisis conceptual e interpretativo sobre este segmento. De este modo, se partió del estudio cualitativo pautado en la investigación exploratoria, utilizando la investigación bibliográfica y electrónica. Por último, se muestra el ensayo conceptual sobre el volunturismo, que fue elaborado al finalizar el estudio.

PALABRAS CLAVE: Turismo. Voluntariado. Volunturismo.

\section{INTRODUÇÃO}

O turismo apresentou ao longo dos últimos anos um amplo crescimento que refletiu na criação de produtos e serviços cada vez mais diferenciados, sendo direcionados a públicos cada vez mais específicos. Em meio a estes avanços, surge também na área a preocupação com a preservação dos recursos naturais por ele utilizados, tornando-se este um importante fator para seu desenvolvimento. Além disso, observa-se também que a inquietação com o desenvolvimento sustentável extrapolou a questão ambiental e está se acentuando na preocupação também com a relação entre o turismo e a comunidade receptora. Nesse ínterim, vêm se destacando os tipos de turismo que direcionam suas práticas em busca da sustentabilidade, apresentando-se como atividades lucrativas e geradoras de impactos positivos.

Assim, o volunturismo, ou turismo voluntário, apresenta-se no contexto atual como um promissor mercado para os próximos anos, que compreende práticas sustentáveis e gera benefícios para os que delas participam: o turista, o ambiente e a comunidade.

Mundialmente conhecida, esta é uma prática bastante comum em alguns países como a Austrália e os Estados Unidos, já em outros, como no Brasil, por exemplo, o volunturismo ainda não é muito popular e não possui tantos adeptos brasileiros, mas se nota pela quantidade de projetos já existentes ${ }^{1}$ que esta prática encontra-se inserida no mercado brasileiro.

Porém há a carência de bibliografia acadêmica e/ou especializada em nível nacional que esclareça e explique tal prática. Embora a mesma ainda seja incipiente neste âmbito, é possível encontrar diversas publicações em revistas comerciais da área que abordam a temática. Já em nível internacional é possível verificar que a quantidade de pesquisas sobre a área vem crescendo ao longo dos últimos anos e em sua grande maioria constituída por estudos de caso sobre diversos temas (percepção de volunturistas e residentes, impactos da atividade, os reais benefícios - ou não - da atividade, entre outros).

Tais informações podem ser constatadas em pesquisa eletrônica realizada em buscadores na internet (Google, Ask, Bing, Yahoo) com o termo "volunturismo", que neste caso encontram-se aproximadamente 9 mil páginas, enquanto o termo "voluntourism" apresenta quase 700 mil páginas. Filtrando a busca no "Google Scholar" (Google Acadêmico), o termo em português apresenta apenas 16 páginas e em inglês, 698 páginas. Pesquisando obras em língua estrangeira que tratem sobre a temática em questão em base de dados como "Ebrary", encontram-se 155 obras disponíveis.

Já no caso dos periódicos especializados da área de turismo, há poucas publicações tratando sobre o tema de modo teórico, sendo que também é mais comum a presença de estudos de caso, impactos do segmento, perfil ou percepção de volunturistas. Investigou-se a temática nos textos

1 Para mais conhecimento sobre alguns dos projetos desenvolvidos atualmente no Brasil que trabalham com a proposta do volunturismo, basta acessar o seguinte link: <http://planetasusten tavel.abril.com. br/noticia/desenvolvimento/volunturismo-brasil-pais-salvar-planeta-538266.shtml. 
dos últimos 3 anos presente nos principais periódicos especializados na área e qualificados pela Coordenação de Aperfeiçoamento de Pessoal de Nível Superior (CAPES) como B1 e B2, quais sejam: "Pasos: El Salul"; "Estudios e Perspectivas en Turismo"; "Turismo em Análise"; "Turismo: Visão e Ação"; "Caderno Virtual de Turismo".

Deste modo, identificou-se a necessidade de obter informações mais concretas a respeito da referida atividade, uma vez que ela ainda não apresenta um conceito difundido. Mas por que ela é necessária? Conhecê-la mais a fundo talvez indique o caminho mais adequado para o alcance da sustentabilidade turística, ou até mesmo desmistifique a ideia de que finalmente se consegue fazer turismo com o mínimo de impactos negativos. Enfim, são inúmeras as inquietações e as abordagens que esta temática ainda deve gerar, mas antes disso, deve-se investigar se volunturismo caracterizase como turismo, pois todos os outros questionamentos não podem ser solucionados sem que antes seja definido o que é o objeto de estudo.

Assim, é necessário compreendê-lo melhor, partindo de sua base conceitual, ponto ainda pouco discutido no âmbito acadêmico da área de turismo. Então, neste artigo, busca-se esclarecer e conceituar a atividade denominada de "volunturismo".

Portanto a relevância deste estudo se dá principalmente pelo fato de que ainda não existe um conceito claro de tal prática, bem como por possibilitar uma discussão relativamente nova no meio acadêmico de turismo, já que a maior parte das pesquisas em turismo trata de assuntos amplamente abordados ou de estudos de caso isolados que não fornecem uma base conceitual mais aprofundada para pesquisas posteriores.

Por fim, entender o que é o "volunturismo" representa iniciar uma caminhada na busca pela compreensão conceitual de tal atividade e esta pesquisa constitui-se em um estudo teórico e qualitativo sobre o "volunturismo", buscando compreender esta atividade e apresentar o seu significado. Caracteriza-se pela pesquisa exploratória, uma vez que objetiva apresentar um conceito para o volunturismo e para isso, parte de um levantamento bibliográfico e eletrônico.

\section{TURISMO: CONCEITUAÇÕES E TENDÊNCIAS}

Embora as primeiras definições das palavras turismo e turista datem do início do século XIX (DIAS; AGUIAR, 2002), atualmente, conceituar turismo ainda gera controvérsias, dada a complexidade de tal atividade. Desde então muitos conceitos foram criados, contestados, revistos e modificados, mas ainda não se chegou a um conceito comumente aceito.

Cooper (2007, p. 40) afirma que esta discussão ainda se encontra destituída de um conceito final, aceito por todos sem contestações e é resultado e reflexo da complexidade que a atividade possui. Por isso, torna-se "difícil encontrar uma coerência sólida na abordagem que define o turismo".

Em razão disso, a academia constata a incipiência de trabalhos que vêm revelando e tratando de aspectos teóricos e epistemológicos do turismo, embora ainda germinados desde um ensaio desejoso de aprofundamento, compartilhamento e aceitação pelos pares pesquisadores. Além disso, nesta trajetória de estudos críticos há também a tentativa de esclarecer e explicar o turismo à luz de novas abordagens (que não a positivista e sistêmica), como por meio da fenomenologia, da complexidade e da transdisciplinaridade (inclusive já mencionados por Jafar Jafari desde o século passado).

Assim, autores como Sonaglio (2013), Medina (2012), Socarrás (2012), Nechar e Panosso Netto (2010), Ramirez (2010), Damián (2010) e Gaxiola (2008), têm publicado textos que interpretam, explicam e esclarecem diversos pontos sobre a teoria e a epistemologia do turismo, o conhecimento do turismo, sobre a estrutura, a dinâmica e o funcionamento do turismo, entre outros aspectos e elementos inerentes ao fenômeno.

Sobre as definições de turismo, o que já se entende como consensual entre estudiosos e pesquisadores já foi relatado por alguns autores como Beni (2001), que destaca três tendências para a definição de turismo: as definições econômicas; as definições técnicas e as definições holísticas. Já Dias (2005) assegura que o turismo pode ser estudado em duas vertentes centrais: a econômica (na qual a atividade é vista como uma indústria), enquanto na outra perspectiva o turismo é visto como uma prática social e cultural. 
Existem outros autores que trazem conceitos de turismo que se encaixam nessas ou em outras tendências e que merecem destaque por serem conceitos relevantes para a análise objetivada. Como, por exemplo, Oscar de La Torre (1992 apud IGNARRA, 2003) que destaca o turismo como um "deslocamento voluntário". Partindo desta premissa, de que toda viagem de turismo é um deslocamento voluntário, toda viagem seria considerada como turismo voluntário. Assim, é importante salientar que toda viagem é sim um movimento voluntário, mas que esta característica não pode ser confundida com o volunturismo, que compreende em sua denominação o fato de serem realizados pelos turistas os chamados "trabalhos voluntários" e não o deslocamento voluntário em si.

Deste modo, em meio a tantos conceitos, observa-se que os mesmos apresentam alguns pontos em comum, que servem para uma melhor compreensão da atividade e que para a pesquisa proposta subsidiarão a formação da base conceitual acerca do referido tema. As características comumente citadas por vários autores como Beni (2001), Sancho (2001), Lohmann, Panosso Netto (2008), Cooper (2007) e Dias (2005), nas definições de turismo, são:

- Viagem ou deslocamento, sem o qual não há turismo;

- Permanência fora do domicílio, elemento vinculado à viagem (alguns dos autores citados destacam também as atividades realizadas durante a viagem);

- Temporalidade, duração da viagem;

- Os bens e os serviços turísticos consumidos pelos turistas para satisfazer suas necessidades.

Frente ao exposto, observa-se que estas são as características básicas que delimitam o que pode, ou não, ser considerado turismo.

Como para o presente estudo a questão das motivações pode vir a ser um fator importante na definição do volunturismo, já que é esta, aparentemente, a mais expressiva diferença entre essa e as outras modalidades de viagens, cumpre apresentar as abordagens a respeito da segmentação turística e das motivações dos turistas destacadas por autores da área.

Com o crescimento do mercado turístico, foram surgindo diferenciados tipos de clientes com características distintas e variadas necessidades a serem satisfeitas. As antigas viagens do turismo de massa, padronizadas, perderam espaço para produtos cada vez mais personalizados, feitos sob medida para os atuais exigentes clientes.

\begin{abstract}
O turismo de grupos, a viagem destinada a todos, sem preocupação com um segmento específico, foram sendo questionadas por pessoas que desejavam viagens mais acessíveis, porém que conseguissem atender às necessidades de cada um. Determinados grupos de consumidores do produto turístico mudam sua postura de vida e não desejam mais viajar com a programação generalizada oferecida pelo turismo de massas. Querem algo mais personalizado, mais direcionado. (MORAES, 1999, p. 19).
\end{abstract}

Assim, identificando essas diferenças entre seus consumidores, o mercado turístico foi se adequando e criando produtos direcionados especificadamente a públicos particulares. Surgem os novos segmentos do mercado turístico, o turismo de negócios, o turismo religioso, o turismo de eventos, entre outros, cada um direcionado a um público específico e com particularidades direcionadas a atender às necessidades de tais consumidores.

Há uma diversidade de critérios que geram várias segmentações distintas no mercado turístico. Observa-se que a segmentação turística considera critérios relacionados com os consumidores que vão desde fatores psicológicos a questões sociais. Dentre os autores consultados (BENI (2001); MORAES (1999); LOHMANN, PANOSSO NETTO (2008); ROSE (2002)), nota-se que grande parte considera a questão das motivações de viagem como um fator para segmentar um mercado. Então, explicar esta questão é indispensável, pois se constitui em subsídio de análise posterior, relacionada aos fatores motivacionais do tema deste artigo.

É sabido que quando alguém decide viajar há uma série de variáveis que influenciam a escolha desta pessoa por determinado destino e produto turístico, aliás, ao decidir realizar uma viagem, o indivíduo está sendo motivado por fatores que o impelem a querer viajar. Segundo Sancho (2001, p. 65), "o motivo da viagem representa o estímulo inicial que põe em marcha todo o processo decisório posterior." 
Para Dias (2005, p. 57), "há diversos fatores que influenciam o comportamento do turista, entre os quais a motivação está entre os mais importantes, destacando-se como um dos componentes que tem a capacidade de influenciar o potencial viajante a viajar."

É nesse contexto que estudar as motivações dos turistas para a viagem e para o consumo de determinados produtos se faz necessário, para que se possam compreender as diferenças entre tais motivações e a influência destas nos diferentes tipos de turismo, inclusive no objeto pesquisado, o volunturismo.

Inicialmente, convém questionar: o que é motivação? Segundo Dias (2005), as motivações partem de necessidades que, ao atingirem um nível de intensidade forte, induzem a pessoa a agir para satisfazê-la. Ainda de acordo com o autor, o reconhecimento da necessidade é o primeiro passo de um processo decisório que culmina na compra e pode ter origem em estímulos externos (propaganda, por exemplo) ou internos ao indivíduo (sede, fome, etc.). Os estímulos internos são conhecidos como motivações.

Dentre as teorias motivacionais, uma das mais conhecidas e citadas por diversos autores, como Dias (2005) e Sancho (2001), é a teoria de Maslow, em que ele descreve as necessidades que afetam a todos os indivíduos, dispondo-as hierarquicamente na ordem em que preferencialmente devem ser satisfeitas. Dias (2005, p. 58) destaca que "a teoria de Maslow é importante porque permite compreender que existem fatores psicológicos que interferem no processo de compra e que devem ser sempre considerados ao lado de outros fatores."

Para os autores Lohmann e Panosso Netto (2008), os fatores motivadores, que podem também ser conhecidos como motivacionais, determinam as necessidades pelas quais uma pessoa viaja, podendo ter caráter genérico, referindo-se à motivação para que indivíduos tirem férias,; ou um aspecto mais específico, que um indivíduo tenha para tirar determinadas férias e para escolher um destino específico e em um momento específico.

Cooper et al. (1993 apud SANCHO, 2001) alegam que a motivação tem suas origens em fatores sociais e psicológicos (atitudes, percepções, cultura, etc.), que dão lugar a formas individuais de motivação; e, por fim, de que todo tipo de viagem é afetado por uma imagem orgânica e induzida, sendo estas essenciais para a motivação.

Já Lohmann e Panosso Netto (2008) apontam a personalidade, o estilo de vida, as experiências anteriores, como turista, a história pessoal (e.g. nostalgia) e a imagem (como quer ser visto pelas outras pessoas), como os fatores principais que influem nas motivações de uma pessoa. Para eles, em uma viagem específica, dificilmente um turista é influenciado apenas por uma motivação.

Swarbrooke e Horner (2002) destacam que os principais fatores motivacionais em turismo podem ser: físicos, emocionais, pessoais, desenvolvimento pessoal, status, culturais.

É importante salientar que não existem exatidão e precisão no variado número de motivações para as viagens e que estas podem sofrer alterações de acordo com a importância que adquirem, como afirmam Dias e Aguiar (2002). Assim, existem diversos segmentos de turismo em virtude da diversidade motivacional para as viagens.

\section{VOLUNTARIADO}

\section{O QUE É SER VOLUNTÁRIO?}

O planeta enfrentou nas últimas décadas uma onda de crescimento econômico que elevou os padrões de vida de diversas sociedades, bem como o seu poder de consumo e esse crescimento se refletiu também no turismo.

Além do crescimento de divisas, outras taxas mundiais também vêm aumentando vertiginosamente nas últimas décadas. A desigualdade social, a marginalização e a pobreza não são coisas novas, mas, ao que parece, a diferença entre as classes vem se tornando cada vez maior e mais chocante. É surpreendente saber que em pleno século XXI aproximadamente 1 bilhão de pessoas ainda vive 
com fome no mundo (BILLIONHUNGRY, 2012), ou que no ano de 2009 existiam no Brasil mais de 14 milhões de brasileiros com mais de 15 anos analfabetos, o que correspondia a 9,7\% da população nesta faixa etária (IBGE, 2012).

E é para tentar minimizar esta realidade que em todo mundo milhões de pessoas atuam como voluntários em projetos e Organizações Não Governamentais (ONG's), até mesmo na iniciativa pública e privada, desempenhando as mais variadas funções para contribuir com uma mudança mais significativa.

Segundo as Organizações das Nações Unidas (ONU, [?] apud PORTAL DO VOLUNTÁRIO, 2009), "voluntário é o jovem ou o adulto que, devido ao seu interesse pessoal e ao seu espírito cívico, dedica parte do seu tempo, sem remuneração alguma, a diversas formas de atividades, organizadas ou não, de bem estar social ou outros campos."

Este é o conceito mais difundido para voluntário. Porém algumas ONG's e centros de voluntariado como, por exemplo, o Centro de Voluntariado de São Paulo - CVSP (2012), ONG Riovoluntário (2012) e ONG Parceiros Voluntários (2012), apresentam alguns outros conceitos que fornecem uma ideia mais abrangente do que vem a ser esta atividade.

Algumas definições importantes são apresentadas no site da ONG Centro de Ação Voluntária de Curitiba - CAV (2012). Segundo o mesmo, o voluntário é o indivíduo que, movido pela vontade, assume livremente uma atitude responsável, comprometida, criativa, prazerosa e transformadora perante o mundo. Isso significa que ele está inserido em um contexto no qual percebem problemas e dificuldades, além de identificar a melhor forma de colaborar para a sua resolução ou para amenizálo. Ainda segundo o site, a imagem do voluntariado assistencialista foi substituída pela figura de um voluntário com caráter social mais participativo e cidadão. Já o termo voluntariado representa o movimento de pessoas inseridas no serviço voluntário.

Freire e Lima (2005) entendem o voluntário como a pessoa que doa seu tempo de forma espontânea e não remunerada na busca por soluções para sua comunidade, motivada por valores de participação, ajuda a uma causa ou por indignação com a realidade, construindo assim uma sociedade mais humana e justa. Destacam ainda que o voluntário é alguém que deseja ver sua comunidade crescer e desenvolver-se, contribuindo e fazendo parte de tal processo.

Nota-se no discurso dos autores citados a ênfase que os mesmos dão ao voluntário como um agente de transformação da realidade e colaborador para o seu desenvolvimento.

Segundo Martins (2007 apud GROPPO; ZAMARIAN, 2009, p. 22), o voluntário é o indivíduo que "se engaja momentaneamente, sobretudo em campanhas específicas para tratar de problemas particulares, que não comprometem a sua vida e nem, muito menos, implica em riscos para o sistema social vigente, que o incorpora dinâmica reprodutiva". Esse destaque para o trabalho do voluntário em campanhas específicas se coaduna com o objeto de estudo desta pesquisa, o volunturismo, que tem sua prática mais intensificada e podendo ser mais bem identificada neste tipo de campanha.

Groppo e Zamarian (2009) definem o voluntariado como um conjunto de ações, desenvolvidas sem intento financeiro, ao menos manifesto, que envolvem algum tipo de doação (dinheiro, tempo, conhecimento, etc.), sendo o voluntário o sujeito que se engaja nessas ações para "se doar" e resolver problemas de determinado grupo de pessoas ou de determinada comunidade.

Portanto, para esta pesquisa, o voluntário será tido como um indivíduo que, motivado por diversos fatores, disponibiliza o seu tempo, conhecimento, trabalho, etc., sem ser remunerado financeiramente por isso e em prol de trabalhos e ações que visam ao benefício do próximo, promovendo-lhe melhorias por meio do desenvolvimento de sua comunidade. E o voluntariado é tido como esta prática, de doar 'algo' voluntariamente para alguém ou uma causa. Para isto, tais agentes são motivados pelos mais diversos fatores, que serão explanados a seguir.

Para compreender quais as motivações levam os voluntários a trabalharem em ações de voluntariado, é preciso entender de onde elas vêm e diferenciar o serviço voluntário dos demais tipos de trabalho em benefício do próximo.

Freire e Lima (2005) afirmam que existem algumas distorções a respeito do que é o serviço voluntário. Como, por exemplo, a palavra "doação" que, com frequência, é confundida com tal serviço. Quem doa sangue, segundo as autoras, é considerado um doador e não um voluntário. Mas se ele participa de uma mobilização de uma campanha para doação de sangue, ele atua como 
voluntário. O ponto de diferenciação apontado pelas autoras indica que, para ser considerado como um voluntário, é necessário participar da ação, prestar um serviço, trabalhar nela, usar seu tempo em prol de uma causa e não somente doar algo.

Prosseguindo em sua análise, Freire e Lima (2005) fazem ainda algumas considerações e diferenciações acerca do serviço voluntário. Destacam que o mesmo não pode ser confundido com as ações de caráter assistencialista, já que estas provocam dependência e acomodação no público beneficiado (a comunidade); enquanto o voluntariado busca o desenvolvimento da comunidade, estimulando a sua emancipação e a transformação da sua realidade.

Além disso, o voluntariado também é confundido com o estágio não remunerado, os quais são discutidos pelas autoras. Segundo elas, a diferença entre os dois consiste na motivação, já que ambos partem do princípio de uma atividade realizada sem remuneração. O estagiário busca experiência profissional, age em seu benefício; enquanto o voluntário intenta gerar uma transformação social, agindo em prol do outro.

Outros autores também discutem a respeito da base da atividade voluntária. Renes, Alfaro e Ricciardelli (1996 apud DOCKHORN; WERLANG, 2008) afirmam que a atividade voluntária está baseada na solidariedade e na compaixão frente ao sofrimento dos semelhantes. Neste sentido, os autores destacam que a solidariedade pressupõe o reconhecimento do outro como indivíduo com potencialidades e se dirige à universalização. Isto está intimamente ligado ao conceito de voluntariado, já que esta visa à promoção a todos do direito ao desenvolvimento e ao bem-estar. Fagundes (2005 apud DOCKHORN; WERLANG, 2008) também concorda que o voluntariado está vinculado à solidariedade, ao auxílio ao outro.

Freire e Lima (2005) apontam a solidariedade como a mola propulsora básica do voluntariado, indicando ainda alguns outros fatores, o que as autoras chamam de "forças internas" que levam à solidariedade. Segundo as autoras, estas são as principais expectativas ligadas à decisão de participar de trabalhos voluntários:

- Fortalecimento da cidadania;

- Desenvolvimento pessoal;

- Retribuição de algo que recebeu;

- Motivações religiosas;

- Preencher o tempo de forma útil.

Dentre os diversos conceitos apresentados anteriormente para o voluntário, observa-se que a maioria aponta como principal motivação para tal prática a solidariedade.

Enquanto Almeida (2007, p. 68) afirma que "para o senso comum a solidariedade está fortemente ligada ao campo das emoções. Seria uma sensibilidade para com os menos favorecidos que leva a uma atitude de caridade".

Já em enquete encontrada no site da ONG Centro de Ação Voluntária de Curitiba (2012) sobre as motivações que levam os voluntários a desejarem participar ou a participar de atividades, em um total de 6.532 opiniões, encontra-se o seguinte resultado:

- Por ideal: $22,8 \%$.

- Crescimento pessoal: 47,4\%.

- Motivos religiosos: $3,9 \%$.

- Preencher o tempo: 4,0\%.

- Ser reconhecidos: $1,3 \%$.

- Dar retorno social: $21,8 \%$.

Nota-se com esta enquete que a maioria das pessoas afirma participar de serviços voluntários por crescimento pessoal, enquanto os fatores de retorno social e ideal encontram-se praticamente no mesmo nível; sendo os menos opinados os do reconhecimento, por motivos religiosos e preenchimento de tempo. 
Além disso, é necessário salientar que atualmente o serviço voluntário também é utilizado como uma ferramenta para a autopromoção profissional, visto que muitas pessoas começam a fazer trabalhos voluntários como uma tentativa de se estabelecer em uma empresa ou, para aqueles que já são funcionários, para serem recompensadas por isso. Assim, o fator profissional também se constitui em umas das motivações que levam os indivíduos a serem voluntários.

Dockhorn e Werlang (2008) atentam para a forma como o voluntariado é organizado em diferentes países, em função de fatores econômicos, político-sociais e do nível de desenvolvimento. Ainda de acordo com Fagundes (2005 e 2006 apud DOCKHORN; WERLANG, 2008) quanto à forma de organização do serviço voluntário, quanto mais desenvolvido for o país, mais formais serão essas organizações e irão enfatizar mais as atividades filantrópicas. Já quanto menos desenvolvido for o país, menos formais as estruturas voluntárias, destacando-se as redes de ajuda mútua e autoajuda. Mas mesmo nos países em desenvolvimento existem algumas iniciativas e estruturas organizadas, como o caso do Brasil.

No Brasil, percebe-se que o serviço de voluntariado encontra-se bastante organizado, sendo inclusive regulamentado por uma lei que trata das relações entre o voluntário e as instituições. Trata-se da Lei no 9.608, de 18 de fevereiro de 1998, que dispõe sobre o serviço voluntário, caracterizando-o como:

(...) a atividade não remunerada, prestada por pessoa física a entidade pública de qualquer natureza, ou a Instituição privada de fins não lucrativos, que tenha objetivos cívicos, culturais, educacionais, científicos, recreativos ou de assistência social, inclusive mutualidade. (LEI DO VOLUNTÁRIO, 1998 apud CVSP, 2012).

Dita ainda a referida lei que o trabalho voluntário esteja previsto em contrato escrito (Termo de Adesão entre a entidade, pública ou privada, e o prestador do serviço voluntário, no qual deve constar o objeto e as condições de seu exercício), não gerando vínculo empregatício, tampouco obrigação de natureza trabalhista, previdenciária ou afim. Além disso, segundo a lei, o voluntário pode ainda ser ressarcido por despesas que comprovadamente realizar desempenhando o trabalho voluntário, devendo as mesmas ser autorizadas pela entidade (PARCEIROS VOLUNTÁRIOS, 2012).

Freire e Lima (2005) destacam a importância de tal lei, afirmando que antes da criação da mesma havia uma série de conflitos ocasionados por pessoas que agiam de má fé, e trabalhavam como voluntários em uma instituição e depois processavam a mesma exigindo direitos na justiça do trabalho. Ainda, segundo as autoras, havia casos de instituições que exploravam a mão de obra voluntária na tentativa de reduzir os custos da organização.

É importante frisar, com base no discurso das mesmas, que o trabalho desenvolvido pelo terceiro setor, do qual o voluntariado faz parte, não substitui o do governo, mas sim possibilita uma ação conjunta na busca da resolução de problemas sociais por meio de suas ações.

\section{VOLUNTURISMO}

Pelo fato de o volunturismo ser relativamente recente, o movimento tornou-se mais conhecido na década de 1990, quando as pessoas ficaram mais conscientes da questão da responsabilidade social e quando os chamados anos sabáticos tornaram-se mais populares (VOLUNTOURISM, 2013). Deste modo, apenas há alguns anos e em razão do seu crescimento é que o segmento vem despertando o interesse de pesquisadores e estudiosos da área. Este fato é mais presente em âmbito internacional, já que a maior parte das publicações de cunho científico encontrada na área se trata de estudos realizados fora do Brasil.

Não se sabe ao certo quando o volunturismo foi criado, segundo Capelas Junior (2010):

Há quem diga que o turismo voluntário foi "inventado" pelo pesquisador francês Jacques Cousteau, lá na década de 1980. Como não dispunha de muita verba para contratar ajudantes para suas expedições, o velho lobo-do-mar resolveu abrir vagas para quem se dispusesse a trabalhar de graça pelo simples prazer de experimentar fantásticas aventuras a bordo do Calypso pelos sete mares.

De acordo com o autor, desta experiência não muito turística provavelmente nasceu essa modalidade que vem tomando forma nas últimas décadas e promete crescer nos próximos 
anos. Outros autores, no entanto, apresentam versões diferentes para o surgimento do turismo voluntário.

Segundo o site da ONG internacional VolunTourism (2013), o volunturismo em sua forma atual recebeu grande impulso a partir da fundação do Serviço Voluntário no Exterior (Volunteer Service Overseas), em 1958 e do Corpo de Paz Americano (U.S. Peace Corps), em 1961. No entanto, ainda de acordo com o site, a ligação entre viagens e voluntariado na Era Moderna pode ser relacionada ao trabalho de Herb Feith, em 1951, na Indonésia.

Em 1950, numa conferência internacional de estudantes (World University Service Assembly) em Bombaim, na Índia, a delegação Indonésia desafiou os australianos com uma ideia interessante. Com a partida dos holandeses, a Indonésia estava desesperada com a falta de graduados qualificados. Assim, convidaram os australianos para que pudessem viver e trabalhar na Indonésia, o que supriria a necessidade por profissionais qualificados e proporcionaria aos estudantes australianos a oportunidade de especializar-se e de vivenciar tal cultura. Assim, em 1951, Herb Feith, se tornou o primeiro voluntário australiano a atender ao pedido, partindo para Jacarta para trabalhar como tradutor com o Ministério da Informação Indonésio (BRITTON, 2002).

Vários outros jovens australianos seguiram seus passos e assim o Regime de Voluntariado de Pós-Graduação (Volunteer Graduate Scheme) se estabeleceu. Atualmente o programa é conhecido como Voluntários Australianos Internacionais (Australian Volunteers International) (AVI, 2013).

Estes fatos podem ter pavimentado o caminho para a conexão entre viagens e voluntariado que tem evoluído nos 60 anos desde então (VOLUNTOURISM, 2013). O site afirma ainda que, embora a combinação "férias e voluntariado" tenha se iniciado na década de 1990, o primeiro voluntário de férias foi operado pela Earthwatch, em 1971. A pesquisa do Turismo Voluntário começou no início da década de 1990, mas só iniciou sua expansão entre o fim da década de 1990 e o início dos anos 2000.

Callanan e Thomas (2005) e Ingram (2008) relacionam o surgimento do volunturismo com a atenção dada na década de 1980 à problemática da pobreza, da fome e das desigualdades sociais no mundo, bem como da exploração desenfreada dos recursos naturais pelo turismo de massa e seus impactos negativos às comunidades receptoras.

Os autores destacam que nessa época, quando se iniciaram os primeiros debates sobre formas mais responsáveis de turismo e sustentabilidade, a mídia desempenhou um importante papel na denúncia das desigualdades que estavam acontecendo. A partir de então, surgiram iniciativas de celebridades e empresários que se preocupavam com tais problemas sociais.

Uma das iniciativas mais conhecidas citadas por Ingram (2008) é o 'Live Aid' (ajuda ao vivo), criado em 1984 por Bob Geldof, vocalista da banda irlandesa Boomtown Rats. Após testemunhar a fome na Etiópia, o vocalista retornou ao Reino Unido determinado a ajudar. Sua primeira atitude no combate à fome foi a criação e o lançamento de uma música (Do they know it's Christmas? - Será que eles sabem que é Natal?), que se tornou um sucesso e arrecadou mais de US\$10 milhões para a fome etíope. No ano seguinte, quando a fome se espalhou para o Sudão, ele teve a ideia de criar um super show de rock mundial que angariaria fundos para tal causa. Assim, em 13 de julho de 1985 foi aberto oficialmente o 'Live Aid', que foi transmitido para 110 países e arrecadou mais de US\$ 125 milhões para o combate à fome.

Esta foi uma das primeiras alternativas que se uniram ao entretenimento no combate à fome. Segundo Callanan e Thomas (2005), foi o sucesso de iniciativas internacionais como esta que promoveram os setores do voluntariado e da caridade, popularizando-os. Com isso, eles passaram a receber mais atenção e mais contribuições, proporcionando-Ihes novas oportunidades de promover suas causas. As autoras afirmam ainda que, nos últimos anos, muitas instituições de caridade se uniram com os operadores turísticos para criar captação de recursos, sendo os eventos de angariação de fundos e os projetos de voluntariado as duas principais vertentes de envolvimento de tais operadoras com as instituições de caridade.

Segundo Marriott (1999 apud CALLANAN; THOMAS, 2005), viagens ligadas à caridade têm se tornado um dos setores que crescem mais rápido no mercado.

Conforme McCallin (2001 apud CALLANAN; THOMAS, 2005), cada vez mais instituições de caridade buscam diversificar suas receitas junto às práticas do turismo. Por outro lado, o autor afirma 
que o motivo pelo qual os operadores turísticos e muitos outros negócios se envolvem em projetos sociais e com a comunidade é buscando promover uma imagem de ética e responsabilidade social.

Acredita-se, com base nos autores citados, que o volunturismo surgiu, portanto, da união entre instituições filantrópicas e operadores turísticos na busca por mais recursos. Embora, segundo Ingram (2008), as viagens ao exterior para serviços voluntários tenham se iniciado no começo do século $X X$, tal prática ainda é considerada recente.

Mesmo recente, alguns dados mostram que a atividade vem tomando impulso e gerando resultados econômicos consideráveis para uma modalidade com tão pouco tempo, considerando-se o seu surgimento a partir da década de 1980.

De acordo com dados da Associação de Turismo de Lazer e Educação (2008 apud ORD, 2010), o mercado de volunturismo tem uma demanda anual de 1,6 milhões de volunturistas, que geram um valor entre US\$1,6 e 2,6 bilhões com suas viagens.

Segundo o site da Global Volunteer Tourism Guide (2012), em uma pesquisa com mais de 300 organizações voluntárias de turismo em nível mundial, estima-se que o mercado global tem crescido a um total de 1,6 milhões de turistas voluntários por ano, com um valor entre US\$1,7 e US\$2,6 bilhões. Afirma ainda que se verifica um crescimento mais significativo no setor desde 1990.

É importante destacar também os números referentes às intituições voluntárias, já que são elas um componente indispensável na atividade. Em sua pesquisa sobre o volunturismo, Ingram (2008) afirma que, ao longo das duas últimas décadas, as organizações não governamentais vêm desempenhando um papel fundamental no desenvolvimento das comunidades, em âmbito social, político, cultural, técnico e financeiro. Segundo o autor, em 1951, existiam 832 ONG's internacionais. Em 1990, este número passou para 16.208 e, atualmente, estima-se que existam mais de 40.000 ONG's operando em nível internacional.

Segundo Wearing (200? apud ECOVIAGEM, 2007), "(...) viagens com esse enfoque têm se tornado uma tendência crescente na indústria do turismo e começam a receber atenção dos pesquisadores, que estudam a motivação desses viajantes e o impacto dessas ações."

Embora o segmento ainda não seja muito difundido em países em desenvolvimento, como no Brasil, em várias partes do mundo esta já uma prática bastante comum. "Na Europa, nos Estados Unidos e na Austrália, esses programas são superprocurados. No Brasil ainda engatinhamos e grande parte dos volunturistas é de origem estrangeira. Mas já tem gente descobrindo essa nova forma de viajar (...)." (CAPELAS JUNIOR, 2010).

Conforme destaca a Organização Mundial do Turismo (2004), por ser considerado uma das principais atividades produtivas no mundo, o turismo tem a responsabilidade de desenvolver práticas que visem à sustentabilidade. Nesse contexto, as iniciativas voluntárias vêm contribuindo com a diminuição de impactos negativos e no crescimento de tendências positivas. Destaca, ainda, que tais iniciativas "(...) tornaram-se parte da cadeia produtiva do turismo e embora seu impacto tenha sido mínimo no setor como um todo, estão revelando um enorme potencial para movimentar a indústria em direção à sustentabilidade (...)." (OMT, 2004, p. 8).

Atualmente, já é possível encontrar agências especializadas no assunto que dão o suporte necessário para quem deseja fazer este tipo de viagem, como a I-to-I volunteer (http://www.i-to-i. $\mathrm{com} /$ ), que apresenta inclusive opções de programas de volunturismo no Brasil; além de projetos que recebem turistas voluntários ${ }^{2}$ para realizar as mais variadas atividades, como, por exemplo, o Instituto Ekkobrasil (http://www.ekkobrasil.org.br) e a ONG Iko Poran (http://www.ikoporan.org/).

Tomazos e Butler (2009) afirmam que é difícil dizer o quão difundido é o turismo voluntário. As viagens muitas vezes são consideradas oficialmente apenas como negócios ou lazer, e voluntários internacionais podem evitar declarar seu propósito para as autoridades estrangeiras por medo de ter complicações com papelada (vistos).

Os autores apresentam ainda um estudo sobre a relação entre a quantidade de projetos de voluntariado e o crescimento do volunturismo. De acordo com os dados apresentados, é possível

2 É importante destacar que há projetos e/ou instituições que não denominam os seus voluntários diretamente de "volunturistas", como no caso do Instituto Ekko Brasil, que os denomina como ecovoluntários, porém a prática de recebê-los para atuar voluntariamente em tais projetos se coaduna com os princípios do turismo voluntário e, portanto, pode ser considerada como tal. 
perceber que não há uma relação entre a quantidade de projetos com a população de um país (nem sempre os países mais populosos concentram o maior número de projetos), tampouco quanto ao nível de necessidade (países com menores índices de desenvolvimento humano não necessariamente tem uma grande quantidade de projetos).

Após verificar esses dados, eles fazem uma pesquisa quanto ao crescimento do número de projetos em países que sofreram catástrofes naturais, como o Tsunami na Tailândia, em 2004, por exemplo, pois em 2003, havia apenas 3 projetos em tal país, já em 2005 o número saltou para 138 e em 2007 atingiu a marca de 176 projetos. Fica evidente que em alguns lugares afetados por tais catástrofes o número de projetos se eleva como uma resposta rápida aos acontecimentos, porém isso não é regra. Há locais, como os Estados Unidos, que sofreram com fenômenos naturais, mas que não tiveram um crescimento tão considerável de projetos (em 2005, ano do furacão Katrina, havia 77 projetos nos Estados Unidos, porém em 2007 esse número caiu para 48).

Após a análise de 2.446 projetos que preenchem os critérios (quanto ao tempo de envolvimento dos voluntários, bem como a remuneração de atividades) para serem considerados como projetos de turismo voluntário, Tomazos e Butler (2009) os classificaram em 9 categorias de atividades: bem-estar da comunidade (805), ensino (572), ambiental (502), médico (236), cultural (131), desenvolvimento de negócios (91), construção (54), pesquisa (47), outros (28).

Ao questionar se os projetos de turismo voluntário estão mais concentrados em lugares que já têm um apelo como destino turístico forte, os autores abrem lacuna para uma discussão se o volunturismo não já está tomando as formas do mercado do turismo de massa, deixando o simples 'altruísmo' de lado, para dar espaço a um mercado que alia a propaganda meticulosa e comovente na busca pelo lucro.

Seguindo esta linha de pensamento, cabe destacar a reportagem publicada em um conceituado jornal Europeu, o The Guardian, que alerta para o surgimento de um mercado que lucra com a exploração de crianças para a obtenção de doações de turistas 'comovidos'. Segundo Birrell (2010), antes de se envolver ou decidir gastar com a participação em algum projeto de turismo voluntário, deve-se investigar e refletir sobre o que tal atitude pode causar. $O$ jornalista alerta para uma prática que, segundo ele, vem se tornando comum com o crescimento do turismo voluntário. A denúncia consta de que muitos dos projetos que sensibilizam turistas a querer contribuir para a mudança de vida de crianças em orfanatos, na verdade, não passam de tentativas de lucrar com o que chama de 'mercado da culpa'. Ele afirma que muitas dessas crianças, na realidade, não são órfãs (apenas um quarto dessas crianças realmente perdeu ambos os pais). Elas podem ter sido compradas de pais pobres, raptadas ou simplesmente alugadas.

O jornalista faz duras críticas ao modelo de desenvolvimento do volunturismo. Segundo ele, projetos de voluntariado de curto prazo trazem mais danos do que benefícios à localidade; o fato de os turistas pagarem para exercer determinadas atividades, tira oportunidades de trabalho dos residentes. Além disso, o dinheiro que eles pagam nem sempre é revertido para melhorias para a comunidade, mas sim para os serviços e para as acomodações de que o turista necessita. Ele segue seu discurso confrontando valores e questões éticas quanto ao volunturismo:

\footnotetext{
$\mathrm{Na}$ África, as empresas de turismo jogam uma visita a um orfanato ao lado de alguns dias na praia ou vendo animais selvagens. Os críticos argumentam que tirar fotografias de crianças órfãs, que podem ter visto os pais morrer recentemente, os reduz ao status de leões e zebras na savana. Muitos orfanatos deixam os turistas trabalhar com crianças. Mas o que diríamos se estrangeiros desconhecidos entrassem nas nossas casas para cuidar das crianças? Ficaríamos chocados, então por que os padrões são mais baixos no mundo em desenvolvimento? (BIRRELL, 2010).
}

Birrell (2010) critica o direito absoluto das nações desenvolvidas em interferirem nas nações em desenvolvimento, o fato é que o volunturismo é muito mais sobre a autorrealização dos volunturistas do que sobre as necessidades das nações em desenvolvimento. Segundo ele, o rápido crescimento do volunturismo é como o da indústria da ajuda, "salvando nossas próprias consciências sem avaliar totalmente as consequências para as pessoas que procuram ajudar". 


\section{CONCEPÇÕES}

Diversas concepções/conceituações são apresentadas para esta nova modalidade de turismo e em função de sua recente criação ainda existe pouco material bibliográfico publicado que subsidie uma pesquisa mais aprofundada, se comparado a outras modalidades de turismo, como, por exemplo, o ecoturismo, o turismo de eventos e o turismo rural.

Embora existam várias explicações e conceituações para a prática, a maioria assemelha-se a de Wearing, autor que escreveu um livro sobre o assunto. Wearing (2004 apud ORD, 2010) descreve o turismo voluntário como uma forma de turismo que faz uso das pessoas que estão de férias e se voluntariam para financiar e trabalhar em projetos de conservação em todo o mundo, proporcionando-Ihes viagens alternativas sustentáveis que podem ajudar o desenvolvimento da comunidade receptora, a investigação científica ou a restauração ecológica.

Callanan e Thomas (2005) destacam que o turismo voluntário tem suas raízes no voluntariado, o que significa que os indivíduos oferecem o seu tempo e os seus serviços para melhorar algum aspecto da sociedade. Tais autoras também utilizam o conceito de Wearing (2001) para turistas voluntários, afirmando que os mesmos são os turistas que, por diversas razões, são voluntários de organizações, comprometendo seus feriados ou férias em atividades que podem envolver a ajuda ou a diminuição da pobreza material de alguns grupos na sociedade, a restauração de alguns ambientes ou ainda a investigação de aspectos da sociedade ou do ambiente.

As autoras enfatizam que o turismo voluntário é percebido de forma bidimensional, uma vez que os turistas que trabalham em projetos para melhorar a vida ou o ambiente de uma comunidade geram resultados tanto para os beneficiados quanto para eles mesmos. Tais aspectos serão mais especificados na abordagem das motivações dos volunturistas que será apresentada no decorrer deste estudo.

Ingram (2008) aborda o volunturismo como uma forma de turismo que usa o trabalho voluntário de pessoas em férias para ajudar no desenvolvimento de comunidades ou do ambiente natural, visando fornecer alternativas sustentáveis de viagem. Segundo ele, este tipo de turismo constitui-se em uma combinação da ajuda com alguma forma de viagem de lazer, em que estes dois fatores se sobrepõem, formando um produto turístico considerado alternativo, por se basear em uma viagem 'motivada pelo altruísmo', como o próprio autor destaca.

Para Clemmons (2008 apud NASCIMENTO, 2008), volunturismo é "o conjunto integrado de serviço voluntário para um destino - seus residentes e ambiente - com os elementos tradicionais do turismo - artes, cultura, lazer, história, geografia - daquele destino (...)." Então ele é classificado como turismo por apresentar características pertinentes a atividade, como: envolver o deslocamento de pessoas para fora de seu ambiente natural por menos de 365 dias e por consistirem em viagens realizadas sem a finalidade de obter lucros. Além disso, é considerado como serviço voluntário por implicar a participação ativa do turista na comunidade e no meio ambiente, de forma espontânea, não sendo motivado por ganhos financeiros e incide sobre o bem comum.

Assim, pode-se considerar "turismo voluntário" como sendo uma vertente do turismo, que implica as viagens de turistas para destinos onde desenvolvem trabalhos voluntários, em diversas modalidades, diferenciando-se dos demais tipos de turismo pelo fato de o turista não viajar apenas para conhecer um lugar ou uma cultura diferente. Ele viaja principalmente para desenvolver ações voluntárias sociais ou ambientais custeando sua própria viagem (deslocamentos, alimentação, hospedagem, etc.).

Em uma avaliação inicial, ao que tudo indica, a principal motivação do volunturista parece ser o desejo de ajudar ao próximo, uma vez que está ligado ao voluntariado. Porém as motivações que movem os turistas a participar de tais viagens e atividades são as mais variadas e estão ligadas diretamente ao tipo de volunturista, bem como ao tipo de viagem de volunturismo que se estabelece.

Ingram (2008) cita um estudo realizado por Brown (2005 apud INGRAM, 2008, p. 25) sobre por que as pessoas são voluntárias em suas férias. Segundo o autor, o resultado demonstrou que, além de querer fazer algo por aqueles menos afortunados, a motivação mais forte é a oportunidade que este tipo de experiência proporciona de mergulhar na "autenticidade" de um lugar, vivenciando o local, a cultura e interagindo com as pessoas. De acordo com Ingram (2008), embora o turismo voluntário seja considerado uma forma de turismo motivada pelo altruísmo, há também um elemento de centralidade 
do ego. Na verdade, este tipo de turismo atrai público dos mais variados interesses, passando do inteiramente altruísta ao exclusivamente egocêntrico, interessado unicamente em si mesmo.

O autor explica ainda que, como um produto do turismo de nicho, o volunturismo é também uma forma de consumo. Assim, há aqueles com genuínos motivos altruístas e há os que buscam também um componente de lazer em tais viagens.

Após um levantamento com 76 turistas voluntários de 6 diferentes organizações, Coghlan (2006 apud MCGEHEE, 2006) identificou 2 grupos muito diferentes de volunturistas, distinguidos com base em suas motivações e perfis sociodemográficos: o voluntariado jovem (o colégio, o jovem e o mercado pós-faculdade) e o público maduro (mercado dos 50 anos de idade).

A autora destaca como as principais características do público de turistas voluntários jovens: têm entre 18 e 24 anos; realizaram pouca ou nenhuma (0-3) viagem internacional nos últimos dois anos; não estão muito envolvidos com o projeto ou a causa antes de participar. Suas principais motivações são: desenvolvimento pessoal, novas experiências, divertir-se, descobrir coisas novas, conhecer pessoas novas, ajudar o pesquisador, desenvolver competências e habilidades.

A autora menciona as principais características do público de turistas voluntários maduros: têm mais de 50 anos, geralmente viajam em casais, realizaram quatro ou mais viagens internacionais nos últimos dois anos, estão envolvidos antes de participarem da viagem. Suas principais motivações são: aprender e ajudar o pesquisador, apoio à organização, fazer algo significativo, aprender sobre animais selvagens, experiência de novas culturas, divertir-se.

O levantamento da autora ainda revela que indivíduos com idade entre 30 e 40 anos parecem não ser tão ativos no turismo voluntário baseado na preservação, provavelmente por razões que incluem família, restrições da carreira e obrigações.

Assim, os resultados mostraram que os turistas voluntários de projetos de preservação são realmente motivados por uma mistura de motivações do turismo e de voluntariado. As motivações que foram mais conceituadas em uma escala global de 5 pontos, incluem: "experimentar coisas novas e diferentes", "ter um bom tempo", "participar de uma oportunidade rara", "aumentar o seu conhecimento de conservação e ecologia" e "explorar novos lugares".

São diversas as vertentes de pensamentos que norteiam o estudo das motivações do turista voluntário. Há autores que afirmam que eles são mais motivados por fatores altruístas, pela busca por conhecimento e pela oportunidade de conhecer novos lugares, novas pessoas e de vivenciar culturas diferentes ajudando ao próximo e ao ambiente natural. Porém há também os autores que afirmam não existir somente o desejo de ajudar, mas também o volunturista está em alguns casos, motivado principalmente em seu benefício. Estudos têm questionado as motivações e o desempenho dos turistas voluntários, afirmando que eles estão mais interessados em cumprir objetivos relacionados com o 'eu' (PECADO, 2009 apud ORD, 2010).

Wearing (2001) afirma que os turistas voluntários são diferentes dos turistas regulares porque eles estão interessados em fornecer um aspecto benéfico para suas férias. Há claramente no discurso do autor que o fato de vivenciar culturas e lugares diferentes enquanto desempenha um trabalho voluntário serve para que o turista amplie suas interpretações de 'autoimagem' na descoberta do seu 'eu'. E é esse fator que leva muitos a participarem de uma experiêcia como esta, servir ao próximo enquanto descobre a si mesmo.

Souza e Pazini (2008) afirmam que o turista voluntário é, portanto, um novo tipo de visitante nas localidades, constituindo-se em uma nova demanda viajando a turismo para destinos que necessitam de ajuda dos mais diferentes tipos. Para eles, o perfil do turista voluntário são pessoas que querem mergulhar mais fundo na compreensão da realidade complexa da população, satisfazendo-se em compartilhar, aprender e ajudar na construção de um mundo mais justo para todos.

Podemos dizer que temos um turista viajando para ser voluntário, viajando motivado pela possibilidade de praticar a atividade voluntária e atuando efetivamente como tal no local visitado, e segundo os critérios utilizados para categorização da atividade do turismo como apresentado pela Organização Mundial Turismo - OMT (2005) pode chamá-lo de "Turista Voluntário", e quiçá podemos ousar a dizer que temos aí o surgimento do Turismo Voluntário. (SOUZA; PAZINI, 2008, p. 20).

Frente ao exposto, observa-se que as motivações que impelem os turistas a participar de viagens de turismo voluntário são as mais variadas. Desde conhecer lugares, pessoas e culturas 
novas, adquirir conhecimentos, ajudar ao próximo ou na conservação de ambientes, por lazer, por desenvolvimento pessoal, enfim, há uma mistura de motivações que podem ser identificadas neste tipo de turismo. Por tal razão, há alguns autores que se baseiam nelas para classificar os tipos de volunturistas existentes.

Callanan e Thomas (2005 apud INGRAM, 2008) sugerem que há três níveis para categorizar os volunturistas:

- Na primeira fase, encontra-se o 'turista voluntário raso', que são aqueles interessados em sua autodescoberta, desenvolvimento pessoal e acadêmico. Sugere-se também que este tipo dá mais importância ao destino e às atividades disponíveis além do projeto de voluntariado, podendo-se dizer que ele tem uma "mentalidade de férias", mesmo participando de trabalhos voluntários.

- No segundo nível, está o 'turista voluntário intermediário', que é motivado por dois fatores, o altruísmo e o autoconhecimento. Geralmente ele passa de 2 a 4 meses envolvido no projeto e acredita-se que este é um tempo suficiente para que ele possa contribuir com o projeto. Ele ainda reserva algum tempo de férias para desfrutar do destino.

- A terceira camada é a que predominam os motivos altruístas. Nesta, os volunturistas são conhecidos como 'turistas voluntários profundos', apresentando como principal motivação o altruísmo e em segundo plano a preocupação com seu interesse pessoal.

Quanto a esta classificação, Ingram (2008) destaca que definir o tipo de turista pelo tempo de envolvimento pode, em alguns casos, insinuar que aqueles envolvidos por menos tempo são superficiais e que seu trabalho não gera resultados comparáveis aos de quem se envolve por mais tempo. O autor afirma que o tempo gasto com o voluntariado não pode ser o único indicador de contribuição, uma vez que as pessoas podem contribuir de várias formas. Além disso, participar de projetos deste tipo infere um gasto financeiro que nem todos podem arcar por longos períodos, porém, mesmo em viagens curtas, podem desempenhar um trabalho significativo para os projetos.

O próprio autor explica que os trabalhos reparadores imediatos geram, sim, impacto sobre as comunidades, mas é importante manter os benefícios em longo prazo. Do contrário, não adianta promover uma melhoria hoje sem garantir a sua continuidade. Isso vai variar conforme as configurações em que o projeto se encontra, na maneira como ele está organizado.

Coghlan (2007 apud INGRAM, 2008) identificou três tipos de viagens de volunturismo:

- No primeiro tipo, o volunturista dá grande importância à investigação ou ao trabalho a ser realizado antes da experiência de voluntariado. São viagens que geralmente requerem um compromisso em longo prazo (um período de seis meses ou mais);

- O segundo tipo é a viagem que combina o trabalho no projeto voluntário com elementos do turismo, oferecendo atividades que exploram a cultura local e a paisagem;

- O terceiro tipo é aquele que gera resultados para o volunturista, promovendo-Ihe autodesenvolvimento por meio da interação com a cultura e também a realização de outras atividades.

Pode-se correlacionar a classificação de Coghlan (2007 apud INGRAM, 2008) para os tipos de viagens de turismo voluntário com os tipos de volunturistas indicados por Callanan e Thomas (2005). Deste modo, o primeiro tipo de volunturista corresponderia à viagem de nível três, pois são aqueles que aparentemente se envolvem mais e por mais tempo com a causa, tendo motivos mais altruístas. O tipo dois de viagem corresponderia ao tipo dois de turista, que é aquele mais intermediário, mistura o trabalho voluntário com a prática do turismo em forma de visitas e passeios, enfim, é o meio termo entre o puro turista e o puro voluntário, mescla seus desejos altruístas com seus desejos de lazer. Já o terceiro tipo de viagem corresponderia ao tipo número um de turista, que é considerado menos altruísta que os demais por concentrar suas atividades mais em seu benefício que em prol do projeto em que voluntaria. Como os próprios autores citam, têm uma mentalidade mais ligada ao aspecto do lazer durante a viagem, além de realizar viagens de menor duração.

O turismo voluntário, considerado ainda recente em pesquisas, traz uma infinidade de tendências e de fatores a serem investigados. Ord (2010) e Ingram (2008) afirmam que sua literatura se concentra principalmente nos aspectos ligados ao turista voluntário e suas motivações, bem como aos benefícios 
que ele pode adquirir em viagens deste tipo, desconsiderando questões importantes, como os impactos do volunturismo nas comunidades de acolhimento, além dos resultados de tal prática.

\section{IMPACTOS DO VOLUNTURISMO}

Visando colaborar com o entendimento sobre o assunto abordado, serão explanados apenas alguns aspectos encontrados nas obras dos autores consultados, sem, no entanto, realizar aprofundamento na temática, visto que este não é o foco da pesquisa.

Guttentan (2009 apud ORD, 2010) identifica cinco possíveis áreas de impactos negativos do volunturismo às comunidades:

- Negligência dos desejos da população local;

- Conclusão de um trabalho insatisfatório;

- Diminuição da procura de trabalho e da promoção da dependência;

- Conceituação do outro;

- Mudança cultural.

No entanto o autor destaca que os projetos podem ser gerenciados de forma a evitar estes impactos.

Souza e Pazini (2008) afirmam que este tipo de atividade contribui para a promoção da paz mundial pelo intercâmbio que promove entre os povos e da alteridade entre os indivíduos, bem como na melhoria das condições de vida das comunidades visitadas e na redistribuição de renda em tais destinos.

Para Ingram (2008), o turismo voluntário pode causar tanto impactos positivos quanto negativos, tudo depende do contexto em que está inserido. Se uma organização consegue desempenhar trabalhos e gerar bons resultados em uma localidade, isso não significa que em outra ela conseguirá o mesmo. Como impactos positivos, o autor destaca que o turismo voluntário pode oferecer benefícios para ambas as partes. Enquanto os turistas voluntários auxiliam no atendimento das necessidades da comunidade, eles têm uma oportunidade para o autocrescimento.

No que concerne aos impactos negativos, ele afirma que estes podem ser semelhantes aos de outros nichos, como os mercados de trekking e dos mochileiros, que vêm se massificando e começando a gerar impactos indesejáveis nos destinos receptores. Além disso, destaca também a relação entre os voluntários e a comunidade que pode haver conflitos em virtude da maneira como os volunturistas se portam com relação à comunidade. Segundo o autor, se os voluntários se consideram superiores ou detentores de conhecimento, tal atitude pode ser encarada de forma negativa pela comunidade como imperialista e colonialista. Deste modo, Ingram (2008) afirma ser necessário que as organizações e os projetos trabalhem em conjunto com a comunidade para impedir que o volunturismo se torne um 'novo colonialismo', uma vez que sem o envolvimento da população local há mais chances de uma errada compreensão dos problemas sociais, culturais, ambientais e econômicos de tal região e, portanto, do insucesso.

Para Issac e Platenkamp (2010), a questão principal a ser investigada e desenvolvida é de como criar esperança na educação, saúde e fortalecimento/autonomia da juventude, pois a simples presença de voluntários em uma dada região, como no caso da Palestina, já contribui para a criação de esperança em regiões de conflitos, por exemplo, mas não é o suficiente! Os interessados nesta área precisam ser envolvidos num diálogo polifônico e criar espaços nos quais os participantes possam confrontar opiniões, trocar pontos de vista e sustentar/discutir diferenças sobre seus desentendimentos. Então o resultado destas discussões, ou seja, suas lições, devem ser colocados em uma agenda de discursos no processo da educação, fortalecimento da autonomia dos jovens e da saúde.

\section{NA BUSCA POR UMA COMPREENSÃO DO VOLUNTURISMO}

Observar o paradigma atual do turismo é deparar-se com um cenário no qual a sustentabilidade passou de um mero modismo, lançado na década de 1980 (CORIOLANO; LEITÃO; VASCONCELOS, 2008), para uma real necessidade. 
O mundo assiste, cada vez mais, a catástrofes e desastres naturais. A sociedade vive os sintomas de um sistema em colapso que a condena a colher seus frutos amargos. Em uma economia que oscila, o turismo é visto como um dos principais setores na geração de renda e na oferta de empregos no mundo. Com tanto avanço e tanto desenvolvimento, é conflitante pensar que milhares de pessoas vivem praticamente à margem desta era "globalizada".

Frente a esta realidade, não tão animadora, surgem e se consolidam em todo mundo iniciativas que buscam amenizar as mazelas da atualidade. $O$ voluntariado é uma das formas que a sociedade encontrou para amenizar os problemas causados por suas próprias práticas. Mesmo não sendo uma atividade recente, foi só a partir da década de 1980 (CALLANAN; THOMAS, 2005) (INGRAM, 2008), que ela se popularizou e começou, portanto, a gerar resultados mais perceptíveis.

Não demorou muito para que o turismo se "apropriasse" também desta atividade, nascendo, então, o que se convencionou chamar de volunturismo ou turismo voluntário.

Mas se o volunturismo é uma "mistura" entre turismo e voluntariado, então a qual destas atividades ele pertence? Volunturismo é turismo? Este é o questionamento inicial que se intenta compreender.

A partir das acepções dos autores citados, podem-se expor algumas características básicas do que é considerado volunturismo. Inicialmente, observa-se que ele é um nicho do mercado de turismo, relativamente recente e, portanto, ainda pouco pesquisado. Sua prática consiste em realizar viagens para desempenhar trabalhos voluntários em comunidades ou ambientes naturais, junto a ONG's ou projetos (os turistas podem participar de atividades como cuidar de animais ou monitorar a sua vida no hábitat natural, ou junto à comunidade atuar na construção ou reforma de casas, ou dando aulas para as crianças da comunidade). A principal diferença deste tipo de viagem consiste no fato de que os turistas não vão ao destino somente para realizar atividades de recreação, entretenimento ou descanso, mas também para realizar serviços como voluntário, mesmo durante o seu período de férias. Outro caráter que deve ser mencionado é o fator financeiro de tais viagens, pois uma vez que o turista atua como um voluntário ele não recebe nenhuma remuneração por este tipo de trabalho. Assim, os custos da viagem são de responsabilidade do turista e não do projeto ou da comunidade que $o$ acolhe (geralmente, ele paga uma valor $x$, a operadora negocia as viagens com as ONG's e este valor é, em parte, direcionado ao projeto e parte para as despesas do volunturista durante o período em que fica no destino).

Assim, com base nas explicações do que é considerado turismo (a atividade que compreende o deslocamento de pessoas para lugares diferentes de sua residência habitual, por motivos diversos, excluindo-se o exercício de atividades remuneradas e com o objetivo de satisfazer suas necessidades), e nos elementos que o caracterizam (viagem ou deslocamento, permanência fora do domicílio, temporalidade, bens e serviços turísticos, motivações), bem como no que se define por voluntário/ voluntariado (indivíduo que motivado por diversos fatores disponibiliza o seu tempo, conhecimento, trabalho, etc., sem ser recompensado financeiramente por isso, em prol de trabalhos e ações que visam o benefício do próximo, promovendo-Ihe melhorias através do desenvolvimento de sua comunidade) e por volunturismo (implica as viagens de turistas para destinos, em que desenvolvem trabalhos voluntários, em diversas modalidades, diferenciando-se dos demais tipos de turismo pelo fato de o turista não viajar apenas para conhecer um lugar ou uma cultura diferente, ele viaja principalmente para desenvolver ações voluntárias sociais ou ambientais, custeando sua viagem), considera-se para este estudo que o volunturismo é uma forma de turismo que une o voluntariado às viagens.

Portanto o volunturismo não é desconsiderado turismo somente pelo fato de o turista utilizar o seu tempo de uma forma não convencional como nas viagens do turismo tradicional. Além disso, observa-se que as motivações dos turistas podem ser as mais variadas possíveis. Deste modo, o turista que viaja motivado a realizar serviços voluntários está realmente praticando turismo e não somente o voluntariado (se assim fosse, ele não precisaria se deslocar da sua residência habitual). Esta é apenas a maneira que ele escolhe de utilizar o seu tempo no destino e, portanto, sua viagem possui os elementos característicos de uma viagem turística (motivação, deslocamento, temporalidade, permanência fora da residência e consumo de bens e serviços).

Apresenta-se a seguir um quadro comparativo (Quadro 1), com as principais características do voluntariado e do volunturismo. 
Quadro 1 - Características do Voluntariado e do Volunturismo

\begin{tabular}{|c|c|c|}
\hline \multirow{2}{*}{$\begin{array}{l}\text { Caracterís- } \\
\text { ticas }\end{array}$} & \multicolumn{2}{|c|}{ Tipos de atividades } \\
\hline & Voluntariado & Volunturismo \\
\hline $\begin{array}{l}\text { Palavra- } \\
\text { chave }\end{array}$ & Serviço voluntário & Turismo voluntário \\
\hline Motivação & Solidariedade/ Desenvolvimento pessoal & Altruísmo/Desenvolvimento pessoal \\
\hline Objetivo & $\begin{array}{l}\text { Promover melhorias/benefícios na comu- } \\
\text { nidade ou no ambiente natural na busca } \\
\text { pela resolução de problemas sociais, } \\
\text { econômicos, culturais ou naturais. }\end{array}$ & $\begin{array}{l}\text { Desenvolver ações voluntárias no destino/ } \\
\text { comunidade que promovam a sua sustent- } \\
\text { abilidade social e/ou ambiental. }\end{array}$ \\
\hline Benefícios & $\begin{array}{l}\text { Gera benefícios tanto para o voluntário } \\
\text { (autoconhecimento, obtenção de ex- } \\
\text { periência) quanto para a comunidade } \\
\text { (melhoria da qualidade de vida). }\end{array}$ & $\begin{array}{l}\text { Gera benefícios tanto para o volunturista } \\
\text { (intercâmbio cultural, adquirir conheci- } \\
\text { mentos, lazer, desenvolvimento pessoal) } \\
\text { quanto para a comunidade (intercâmbio } \\
\text { cultural, melhoria da qualidade de vida). }\end{array}$ \\
\hline $\begin{array}{l}\text { Temporali- } \\
\text { dade }\end{array}$ & $\begin{array}{l}\text { Pode ser realizado durante qualquer } \\
\text { período. }\end{array}$ & $\begin{array}{l}\text { Pode ser realizado durante viagens de } \\
\text { férias, ou em outros períodos (ocasiões } \\
\text { particulares como catástrofes, aposenta- } \\
\text { doria, "ano sabático", etc.) }\end{array}$ \\
\hline $\begin{array}{l}\text { Desloca- } \\
\text { mento }\end{array}$ & Não é necessário viajar. & É necessário viajar. \\
\hline $\begin{array}{l}\text { Acomoda- } \\
\text { ção/ } \\
\text { Hospeda- } \\
\text { gem }\end{array}$ & Na própria casa. & $\begin{array}{l}\text { Estabelecimentos de hospedagem como } \\
\text { hotéis e pousadas. }\end{array}$ \\
\hline Localização & $\begin{array}{l}\text { Pode ser realizado na própria comuni- } \\
\text { dade. }\end{array}$ & $\begin{array}{l}\text { É realizado em uma comunidade externa } \\
\text { a própria. }\end{array}$ \\
\hline Vínculo & $\begin{array}{l}\text { Não é necessário estar vinculado a uma } \\
\text { instituição. }\end{array}$ & $\begin{array}{l}\text { Não é necessário estar vinculado a uma } \\
\text { instituição. }\end{array}$ \\
\hline
\end{tabular}

Fonte: Elaborado pelo autor. 
Nota-se pelas características expostas no Quadro 1 que, apesar do volunturismo envolver práticas de voluntariado, ambos conservam particularidades, como, por exemplo, a motivação. Em voluntariado, a maioria dos autores afirma que a solidariedade é a base de tal atividade; enquanto no volunturismo os autores afirmam que é o altruísmo. Porém, como se pode notar, existe outro fator mencionado em ambas as atividades, o desenvolvimento pessoal, que parece ser o principal motivador das mesmas.

As atividades também se assemelham no tocante aos benefícios que são gerados tanto para o voluntário ou o volunturista quanto para a comunidade e quanto ao vínculo do volunturista ou do voluntário com uma instituição. O objetivo de ambas também é bastante similar, porém as demais características são contrárias entre as atividades. Isso ocorre devido ao fato de o volunturismo se constituir de turismo e voluntariado Os fatores diferentes são aqueles ligados à prática do turismo e se não fosse diferente seria o próprio voluntariado.

Outro fator que difere entre ambas, propício a uma discussão, é o fato de que enquanto o voluntariado pode ser realizado em qualquer período, o volunturismo, segundo a maioria dos autores, é realizado durante as férias. Dos autores consultados apenas Ingram (2008) comenta em sua análise o que chama de "ano sabático" (a expressão gap year em inglês) como sendo um período no qual muitos jovens realizam viagens de autoconhecimento e de aprendizagem, como o volunturismo. Este "ano sabático" é o período em que jovens, entre 18 e 25 anos, realizam o que pode se chamar de viagens de autoconhecimento, ou somente de conhecimento, ao redor do mundo e são um público frequente entre os volunturistas. É o "tour" do século XXI, similar ao que os pais enviavam seus filhos no início da atividade turística para a obtenção de conhecimentos.

Enfim, a questão é que, ao citar as "viagens de férias", os autores cometem um equívoco, visto que o público do volunturismo não viaja somente durante as férias. Onde estão os voluntários que viajam para servir em catástrofes? Que vão por livre e espontânea vontade ajudar a quem precisa e, portanto, se não vão a trabalho, são também volunturistas.

Onde estão aqueles que já não trabalham, os aposentados e, portanto, que já não tiram férias? E aqueles que vivem de outras formas de rendimentos financeiros, que viajam sem necessariamente estar de férias? São fatores e públicos que não estão contemplados nas abordagens de tais autores.

Finalmente, considera-se "volunturismo" ou "turismo voluntário" o ato de viajar para um destino com o objetivo principal de desenvolver serviços voluntários no âmbito social e/ou ambiental, sejam estas viagens motivadas por altruísmo ou por interesses pessoais, diferenciando-se dos demais tipos de turismo pelo fato de o turista não viajar apenas para conhecer um lugar, uma cultura diferente, entreterse ou descansar, mas, principalmente, pelo fato de viajar para desenvolver ações voluntárias.

\section{CONSIDERAÇÕES FINAIS}

Este trabalho objetivou um esclarecimento conceitual a respeito do volunturismo ou turismo voluntário, ainda pouco discutido pelos pesquisadores da área. Por esta razão, encontrou-se significativa dificuldade em reunir material bibliográfico para a formação da base conceitual do mesmo, embora tal empecilho não tenha prejudicado a sua concepção, uma vez que o almejado era uma análise inicial do assunto, com vistas a contribuir para formação de uma discussão principiante no âmbito acadêmico acerca do conceito de volunturismo e suas principais características.

Como objetivo principal, esclareceu-se o que é volunturismo, contextualizando-o com suas duas atividades base - o turismo e o voluntariado.

O tema abordado é fonte de diversas inquietações motivadoras de outras discussões que contribuirão para a formação do referencial teórico da atividade como os impactos de tal prática nas comunidades, a sua relação com os volunturistas, as suas motivações, os tipos de volunturistas e de viagens, o real benefício do volunturismo ou o seu real objetivo.

Esta pesquisa não almejou responder a tais questionamentos, visto que em sua metodologia não foram empregadas técnicas de pesquisas que subsidiassem tal feito, porém se reconhece a importância de analisar criticamente tais fatores para que o crescimento desta modalidade possa se realizar da maneira mais acertada possível, não tornando a desgraça humana como um espetáculo 
aproveitado pelo turismo, como alguns autores da área já afirmam e Ingram (2008) é um dos que criticam categoricamente tal aspecto.

Dentre as diversas modalidades de turismo, o volunturismo se apresenta no contexto atual como uma forma sustentável social e ambiental da atividade, diferenciando-se do turismo tradicional principalmente pelas motivações de seus participantes e pelo fato de unir o trabalho voluntário às viagens.

Esta não é ainda uma prática muito difundida em países como o Brasil, apesar de algumas instituições já trabalharem recebendo turistas voluntários. O conceito de volunturismo ainda não faz parte do entendimento comum, tampouco do acadêmico (muitos estudantes da área sequer ouviram falar antes em turismo voluntário).

Por fim, o volunturismo apresenta-se no contexto atual como um segmento do turismo que, em essência, busca impactar de maneira positiva as localidades onde se desenvolve por meio da atuação de turistas junto à comunidade e ao ambiente natural, por meio de ações que unem o turismo e o voluntariado em prol do bem comum e do desenvolvimento sustentável.

\section{REFERÊNCIAS}

ALMEIDA, João Carlos. Antropologia da Solidariedade. 2007. Disponível em: <http://www.hottopos. com/notand14/joao.pdf> Acesso em: 26 maio 2012.

AUSTRALIAN VOLUNTEERS INTERNATIONAL. Our Story. 2013. Disponível em: <http://www. australianvolunteers.com/about-us-/who-we-are/our-story.aspx>. Acesso em: 20 mar 2013.

BENI, Mário Carlos. Análise estrutural do turismo. 6. ed. São Paulo: SENAC, 2001.

BILLIONHUNGRY. Assine a petição para acabar com a fome. 2012. 1vídeo. Disponível em : <http:// www.1billionhungry.org/> Acesso em: 23 maio 2012.

BIRRELL, Ian. Before you pay to volunteer abroad, think of the harm you might do. The Guardian, 2010. Disponível em: < http://www.guardian.co.uk/commentisfree/2010/nov/14/orphans-cambodiaaids-holidays-madonna?INTCMP=SRCH>. Acesso em: 20 mar 2013.

BRITTON, Petter. The history of Australian Volunteers International begins in Indonesia. Inside Indonesia, No 70. Abr-jun 2002. Disponível em: <http://www.insideindonesia.org/feature-editions/ australians-volunteer>. Acesso em: 20 mar 2013.

CALLANAN, Michelle; THOMAS, Sarah. Volunteer tourism: Deconstructing volunteer activities within a dynamic environment. In: NOVELLI, Marina. Niche Tourism: contemporary issues, trends and cases. Tradução Michael Nataupsky. Editora: BUTTERWORTH-HEINEMAN, 2005, cap. 15. p. 183-185.

CAPELAS JUNIOR, Afonso. Volunturismo: no caminho do bem. 2010. Disponível em: <http://planetasustentavel.abril.com.br/noticia/desenvolvimento/volunturismo-brasil-pais-salvar-planeta-538266.shtml > Acesso em: 26 maio 2012.

CENTRO DE AÇÃO VOLUNTÁRIA DE CURITIBA - CAV. Por que você é ou quer ser voluntário?. 2012. Disponível em: <http://www.acaovoluntaria.org.br/enquete/resultado.asp> Acesso em: 22 maio 2012.

CENTRO DE VOLUNTARIADO DE SÃO PAULO - CVSP. Seja Voluntário: Legislação. 2012. Disponível em: <http://www.voluntariado.org.br/seja_voluntario/legislacao.htm> Acesso em: 26 maio 2012.

COOPER, Chris. et al. Turismo: princípios e práticas. Tradução Alexandre Salvaterra. Porto Alegre: Bookman, 2007.

CORIOLANO, Luzia Neide Menezes T.; LEITÃO, C. S.; VASCONCELOS, F. P. Sustentabilidades e Insustentabilidades do Turismo Litorâneo (Sustainability and Unsustainability of Coastal Tourism). Revista da Gestão Costeira Integrada, v. 8, n. 2, set. 2008. Disponível em: http://www.aprh.pt/rgci/pdf/RGCI130_Coriolano.pdf. Acesso em: 22 maio 2012.

DAMIÁN, Alfonso Gonzáles. Posturas subyacentes sobre orden y acción social em las teorias del turismo. In: NECHAR, Marcelino Castillo; PANOSSO NETTO, Alexandre (Orgs.). Epistemología del turismo: estúdios críticos. México: Trillas, 2010. 
DIAS, Reinaldo. Introdução ao turismo. São Paulo: Atlas, 2005.

DIAS, Reinaldo; AGUIAR, Marina Rodrigues de. Fundamentos do Turismo: conceitos, normas e definições. Campinas, SP: Editora Alínea, 2002.

DOCKHORN, Carolina Neumann de Barros Falcão. WERLANG, Blanca Susana Guevara. Programa CVV: Prevenção do suicídio no contexto das hotlines e do voluntariado (CVV Program: suicide prevention in the context of hotlines and volunteering). Revista Textos e Contextos, Porto Alegre, v. 7, n. 2, p. 183-198. jul./dez. 2008. Disponível em: <http://revistaseletronicas.pucrs.br/ojs/index.php/fass/article/ viewFile/4817/3636> Acesso em: 26 maio 2012.

ECOVIAGEM. "Turismo voluntário"' conquista adeptos no Brasil e pelo mundo. 2007. Disponível em: <http://ecoviagem.uol.com.br/noticias/turismo/turismo-cultural/-turismo-voluntario-conquistaadeptos-no-brasil-e-pelo-mundo-7476.asp> Acesso em: 26 maio 2012.

ECOVIAGEM. Volunturismo mobiliza comunidade na Chapada dos Veadeiros. 2009. Disponível em: <http://ecoviagem.uol.com.br/noticias/turismo/turismo-nacional/volunturismo-mobiliza-comunidade-nachapada-dos-veadeiros-9613.asp> Acesso em: 26 maio 2012.

FREIRE, Sully Campos. LIMA, Tatiana da Silva Lucas Tavares de. Perspectivas do voluntariado no turismo. Recife, PE: 2005, 95p. Originalmente apresentada como trabalho de conclusão de curso. Universidade Federal de Pernambuco, 2005. Disponível em: <http://portaldovoluntario.org.br/documents/0 000/0165/111902297073.pdf> Acesso em: 26 maio 2012.

GAXIOLA, Napoleón Conde. Hermenêutica dialética transformacional aplicada al turismo, el derecho y las ciencias sociales. México: Instituto Politécnico Nacional, 2008. Disponível em: <http://site.ebrary. com/lib/alltitles/docDetail.action?docID=10418001\&ppg=156>. Acesso em: 29 mar. 2013.

GLOBAL VOLUNTEER TOURISM GUIDE. How big is it?. 2012. Trad. Michael Nataupsky. Disponível em: <http://www.globalvolunteertourismguide.com/greetings.html> Acesso em: 26 maio 2012.

GROPPO, Luís Antonio. ZAMARIAN, Maria Jussara. Juventude e voluntariado: considerações sobre o novo modelo de participação social e os jovens no Brasil. 2009. Disponível em: <http://www.google.com. $\mathrm{br} /$ search $? q=$ Juventude $+e+$ voluntariado $\% 3 A+$ considera $\% C 3 \% A 7 \% C 3 \% B 5 e s+$ sobre $+o+$ novo + modelo + de + participa $\% C 3 \% A 7 \% C 3 \% A 30+$ social+e+os + jovens + no + Brasil\&ie $=u t f-8 \& o e=u t f-8 \& a q=t \& r l s=o r g$. mozilla:pt-BR:official\&client=firefox-a > Acesso em: 26 maio 2012.

IGNARRA, Luiz Renato. Fundamentos do turismo. São Paulo: Pioneira Thomson Learning, 2003.

INGRAM, Joanne M.. Volunteer Tourism: Does it have a place in development? Trad. Michael Nataupsky. Tasmania: 2008. 66p. Submitted in fulfilment of the requirements for the degree of Bachelor of Arts with Honours. University of Tasmania, 2008. Disponível em: <http://eprints.utas. edu.au/9349/2/ Honours_Thesis_2008.pdf> Acesso em: 22 maio 2012.

INSTITUTO BRASILEIRO DE GEOGRAFIA E ESTATÍSTICA - IBGE. PNAD 2009: rendimento e número de trabalhadores com carteira assinada sobem e desocupação aumenta. 2012. Disponível em: http://www. ibge.gov.br/home/presidencia/noticias/noticia_visualiza.php?id_noticia=1708\&id_pagina $=1>$. Acesso em: 25 maio 2012.

LOHMANN, Guilherme; PANOSSO NETTO, Alexandre. Teoria do turismo: conceitos, modelos e sistemas. São Paulo; Alpeh, 2008.

MCGEHEE, Nancy. Choosing Your Conservation-based Volunteer Tourism Market Segment With Care - Part I. 2006. Tradução Michael Nataupsky. Disponível em: <http://www.voluntourism. org/newsstudyandresearch0106.htm> Acesso em: 12 maio 2012.

MEDINA, Antonio Diáz. Turismo y conocimiento científico, un primer acercamiento. 2a Convención Internacional de Estudios Turísticos. Havana/Cuba, 18 a 22 jun, 2012. Disponível em: <http://site.ebrary. com/lib/alltitles/docDetail.action?docID=10592318\&ppg=72>. Acesso em: 03 abr. 2013.

MORAES, Claúdia Corrêa de Almeida. Turismo - segmentação de mercado: um estudo introdutório. In: ANSARAH, Marília dos Gomes do Reis. Turismo: segmentação de mercado. São Paulo: Futura, 1999, cap. 1, p. 13-33. 
NASCIMENTO, Angélica. Turismo e voluntariado. 2008. Disponível em: <http://portaldovoluntario.org. br/blogs/54354/posts/1466> Acesso em: 26 maio 2012.

NECHAR, Marcelino Castillo; PANOSSO NETTO, Alexandre. Implicaciones epistemológicas en la construcción del conocimiento del turismo. In: NECHAR, Marcelino Castillo; PANOSSO NETTO, Alexandre (Orgs.). Epistemología del turismo: estúdios críticos. México: Trillas, 2010.

ORD, Cynthia. Contribution of Volunteer Tourism to Organic Farms: An analysis of the WWOOF exchange in Canada. University of the Balearic Islands, Palma de Mallorca, Spain: set. 2010. Tradução Michael Nataupsky. Disponível em: <http://www.ecoclub.com/articles/502-volunteer-tourism-organicfarms> Acesso em: 22 maio 2012.

ORGANIZAÇÃO MUNDIAL DO TURISMO - OMT. Iniciativas voluntárias para o turismo sustentável: inventário mundial e análise comparativa de 104 selos ecológicos, prêmios e iniciativas de autocomprometimento. Tradução Gabriela Scuta Fagliari. São Paulo: Roca, 2004.

PARCEIROS VOLUNTÁRIOS. Lei do Voluntariado. 2012. Disponível em: <http://www.parceirosvoluntarios.org.br/Componentes/Programas/LeiVoluntariado.asp> Acesso em: 26 maio 2012.

PLATENKAMP, V.; ISAAC, Rami K. Volunteer tourism in Palestine: a normative perspective. In: MOUFAKKIR, Omar Kelly I (Org.). Tourism, progress and peace. Wallingford/Oxon/Grã Bretanha: CABI Publishing, 2010. Disponível em: <http://site.ebrary.com/lib/alltitles/docDetail.action?docID=10389899\&ppg=180>. Acesso em 22 mar. 2013.

PORTAL DO VOLUNTÁRIO. O que é ser voluntário? 2009. Disponível em: <http://portaldovoluntario. org.br/blogs/54329/posts/45> Acesso em: 26 maio 2012.

RAMIREZ, Carmen Urdaneta. Reflexiones sobre epistemologia del turismo. In: NECHAR, Marcelino Castillo; PANOSSO NETTO, Alexandre (Orgs.). Epistemología del turismo: estúdios críticos. México: Trillas, 2010.

RIOVOLUNTÁRIO. O que é ser voluntário? 2012. Disponível em: <http://www.riovoluntario.org.br/> Acesso em: 26 maio 2012.

ROSE, Alexandre Turatti de. Turismo: planejamento e marketing. São Paulo: Editora Manole, 2002.

SANCHO, Amparo. Introdução ao turismo. Tradução Dolores Martin Rodriguez Corner. São Paulo: Roca, 2001.

SOCARRÁS, Alberto J. Pérez. Uma propuesta teórica y metodológica para lós estúdios del turismo desde la perspectiva de la complejidad. $2^{\mathbf{a}}$ Convención Internacional de Estudios Turísticos. Havana/Cuba, 18 a 22 jun, 2012. Disponível em: <http://site.ebrary.com/lib/alltitles/docDetail. action?docID=10592318\&ppg=72>. Acesso em: 03 abr. 2013.

SONAGLIO, Kerlei Eniele. Transdisciplinar o turismo: um ensaio sobre a base paradigmática. Pasos (El Salul) Revista de Turismo y Patrimonio Cultural. Espanha, v. 11, n. 1, p. 205-216, jan. 2013. Disponível em: <http://www.pasosonline.org/Publicados/11113/PS0113 15.pdf>. Acesso em: 11 abr. 2013.

SOUZA, Claudio Alexandre de; PAZINI, Thais Akemi Yoshida. Turismo e o voluntariado - casos brasileiros. Revista ECETUR, 2008, cap. 2, p. 17-26. Disponível em: <http://ecetur.aems. com.br/ download/ revista_ecetur.pdf> Acesso em: 22 maio 2012.

SWARBROOKE, John; HORNER, Susan. O comportamento do consumidor no turismo. Tradução Saulo Krieger. São Paulo: Aleph, 2002.

TOMAZOS, K; BUTLER, R. Volunteer tourism: the new ecotourism? 2009. Disponível em: <http:// strathprints.strath.ac.uk/16612/1/strathprints016612.pdf>. Acesso em: 20 mar 2013.

VOLUNTOURISM. VolunTourism - Historical Timeline Prior to 2000. 2013. Disponível em: <http:// www.voluntourism.org/inside-history.html>. Acesso em: 20 mar 2013. 


\section{Turismō}

Disponível em: www.univali.br/revistaturismo

WEARING, Stephen. Volunteer Tourism: experiences that make a difference. CABI Publishing: 2001. Versão eletrônica. Tradução Michael Nataupsky. Disponível em: <http://books.google.com/ books?id=6V RrdFoCCDwC\&printsec $=$ frontcover\&dq $=$ stephen + wearing\&source $=$ bl\&ots $=$ gu8BSDiHjZ\&sig $=S 6 I k c x 8 C X K$ 6ZytLIf-TpEWeMDhw\&hl=en\&ei=VALeTJjHHYP7Iwfi3cyMDQ\&sa =X\&oi=book_result \&ct=result\&resnum $=7$ $\& s q i=2 \& v e d=0 C E E Q 6 A E w B g \# v=$ onepage\&q\&f=false $>$ Acesso em: 22 maio 2012. 